\title{
The many faces of ubiquitinated histone H2A: insights from the
} DUBs

\author{
Joseph HA Vissers $^{\dagger 1}$, Francesco Nicassio ${ }^{\dagger 2}$, Maarten van Lohuizen ${ }^{1}$, \\ Pier Paolo Di Fiore $2,3,4$ and Elisabetta Citterio*1
}

Address: ${ }^{1}$ Division of Molecular Genetics, The Netherlands Cancer Institute, Plesmanlaan 121, 1066 CX Amsterdam, The Netherlands, ${ }^{2}$ IFOM, Istituto FIRC di Oncologia Molecolare, Via Adamello 16, 20139, Milan, Italy, ${ }^{3}$ Istituto Europeo di Oncologia, Via Ripamonti 435, 20141, Milan, Italy and ${ }^{4}$ Dipartimento di Medicina, Chirurgia ed Odontoiatria, Universita' di Milano, 20112, Milan, Italy

Email: Joseph HA Vissers - j.vissers@nki.nl; Francesco Nicassio - francesco.nicassio@ifom-ieo-campus.it; Maarten van Lohuizen - m.v.lohuizen@nki.nl; Pier Paolo Di Fiore - pierpaolo.difiore@ifom-ieo-campus.it; Elisabetta Citterio* - e.citterio@nki.nl

* Corresponding author †Equal contributors

Published: 22 April 2008

Cell Division 2008, 3:8 doi:10.1186/1747-1028-3-8

This article is available from: http://www.celldiv.com/content/3/l/8

(C) 2008 Vissers et al; licensee BioMed Central Ltd.

This is an Open Access article distributed under the terms of the Creative Commons Attribution License (http://creativecommons.org/licenses/by/2.0), which permits unrestricted use, distribution, and reproduction in any medium, provided the original work is properly cited.

Received: 19 March 2008

Accepted: 22 April 2008

\begin{abstract}
Monoubiquitination of $\mathrm{H} 2 \mathrm{~A}$ is a major histone modification in mammalian cells. Understanding how monoubiquitinated $\mathrm{H} 2 \mathrm{~A}(\mathrm{uH} 2 \mathrm{~A}$ ) regulates DNA-based processes in the context of chromatin is a challenging question. Work in the past years linked $\mathrm{uH} 2 \mathrm{~A}$ to transcriptional repression by the Polycomb group proteins of developmental regulators. Recently, a number of mammalian deubiquitinating enzymes (DUBs) that catalyze the removal of ubiquitin from $\mathrm{H} 2 \mathrm{~A}$ have been discovered. These studies provide convincing evidence that $\mathrm{H} 2 \mathrm{~A}$ deubiquitination is connected with gene activation. In addition, $\mathrm{uH} 2 \mathrm{~A}$ regulatory enzymes have crucial roles in the cellular response to DNA damage and in cell cycle progression. In this review we will discuss new insights into uH2A biology, with emphasis on the H2A DUBs.
\end{abstract}

\section{Background}

Conjugation of ubiquitin (Ub) occurs through the concerted action of an ATP-dependent Ub-activating enzyme (E1), a Ub conjugating enzyme (E2), and a Ub ligase (E3) [1]. The 76-amino acid protein $\mathrm{Ub}$ can be conjugated to target proteins in multiple ways, conferring a high potential of diversity to Ub-mediated signaling [2]. As a monomer, Ub can be linked to one (monoubiquitination) or several lysines (multiple monoubiquitination) on target proteins. In addition, Ub has seven lysine residues which can be modified to form polyubiquitin chains. Lysine 48linked Ub chains generally target proteins for proteolytic destruction. In contrast, monoubiquitination as well as chain formation through lysine 63 have a regulatory role in various processes, including endocytosis, DNA repair, transcription and chromatin regulation [2]. Ubiquitin signaling is transduced by the so called "ubiquitin receptors', proteins which utilize ubiquitin binding domains to interact with ubiquitinated targets [3].

Processes that impact on DNA, such as transcription, DNA replication, DNA repair and mitosis have in common the ability to perform DNA transactions in the chromatin environment. Histones are essential proteins that compact the DNA in the basic unit of chromatin, the nucleosome. In the nucleosome core particle, a tetramer of (H3H4)2 is flanked by two dimers of H2A-H2B to form the histone octamer, around which $146 \mathrm{bp}$ of DNA is wrapped [4]. Core histones interact with the DNA and with each other through a histone fold domain. In addi- 
tion, their unstructured $\mathrm{N}$-terminal or C-terminal (in the case of $\mathrm{H} 2 \mathrm{~A}$ and $\mathrm{H} 2 \mathrm{~B}$ ) "tails" protrude from the nucleosome and provide sites for covalent modification by a variety of enzymes. Histone modifications act both directly (affecting contacts between nucleosomes) and indirectly (through the recruitment of non-histone proteins) in order to orchestrate chromatin environment [5]. It has become clear that covalent modifications ("marks") can influence one another and their combination has been proposed to constitute a "histone code" that regulates chromatin-based processes [6].

Monoubiquitination of histone $\mathrm{H} 2 \mathrm{~A}$ is one of the most abundant histone modifications in mammalian cells. The ubiquitination site has been mapped to lysine 119 (K119) on the carboxyterminal tail of $\mathrm{H} 2 \mathrm{~A}$ and monoubiquitinated $\mathrm{H} 2 \mathrm{~A}(\mathrm{uH} 2 \mathrm{~A})$ has been estimated to comprise between $5-15 \%$ of H2A. Histone H2B is monoubiquitinated at $\mathrm{K} 120$ in about $1 \%$ of total H2B [7-10]. Despite $\mathrm{H} 2 \mathrm{~A}$ being the first protein shown to be ubiquitinated, the function of $\mathrm{uH} 2 \mathrm{~A}$ has remained obscure for a long time. Only recently, the discovery that the Polycomb protein complex Ring1A/B-Bmi1 is a major E3 ligase targeting $\mathrm{H} 2 \mathrm{~A}$, strongly linked $\mathrm{uH} 2 \mathrm{~A}$ to gene silencing and tumor development [11-14]; reviewed in [15]. Accumulating evidence supports an additional role of $\mathrm{uH} 2 \mathrm{~A}$ in the maintenance of genome integrity, further highlighting the potential impact of this modification on neoplastic cell growth [16-21].

Ubiquitination of $\mathrm{H} 2 \mathrm{~A}$ is dynamic, as suggested by the observations that global levels of $\mathrm{uH} 2 \mathrm{~A}$ vary during the cell cycle [22-25]. Accordingly, the existence of several mammalian H2A de-ubiquitinating enzymes (DUBs) has recently been reported. These include members of two distinct protease families [26]. In particular, 2A-DUB belongs to the JAMM/MPN+ family, while USP3, Ubp-M (USP16), USP2 1 and USP22 are part of the USP (Ubiquitin Specific Protease) family $[17,24,25,27-29]$ (Table 1 ). In this review we discuss new findings on how $\mathrm{uH} 2 \mathrm{~A}$ might regulate transcription, as well as the emerging roles of $\mathrm{uH} 2 \mathrm{~A}$ in DNA damage signaling and cell cycle progression. The focus will be on the lessons learned from the H2A DUBs.

\section{uH2A in gene repression}

The role of $\mathrm{uH} 2 \mathrm{~A}$ in transcription has been controversial (reviewed in $[9,10]$ ). Only recently, the characterization of the Polycomb repressive complex PRC1 as ubiquitin ligase for $\mathrm{H} 2 \mathrm{~A}$ strongly linked this modification to silencing of developmental control genes and to X-inactivation. Ring1A and Ring1B (RING1 and RNF2 in man), which harbor a RING domain, are the active E3 ligase components of the complex and are responsible for the deposition of bulk monoubiquitinated H2A ([11-14]; reviewed in [15]) (Table 2). In agreement with a repressive role, uH2A levels at Polycomb-repressed promoters decrease in Ring1A/B deficient cells and this is accompanied by an induction of expression of target genes $[11,13]$. In addition to PRC1, Ring1B has been found in separate repressive complexes containing E2F-6 [30] and the Fbxl10 (JHD1B) and BcoR corepressors [31,32], respectively.

Using different approaches, recent work shows that DUBs for $\mathrm{UH} 2 \mathrm{~A}$ play functional roles in gene activation, providing independent evidence that $\mathrm{uH} 2 \mathrm{~A}$ antagonizes transcription. In this section we will briefly summarize the findings with respect to gene expression regulation obtained with the H2A DUBs Ubp-M (USP16), USP21, 2A-DUB, and USP22 [24,25,27-29] (Table 1). This will be followed by a more detailed discussion of the potential effects of $\mathrm{uH} 2 \mathrm{~A}$ on different phases of transcription. Finally, clues to the mechanistic aspects of uH2A-mediated repression that arise from these and other studies will be presented.

Table I: Mammalian H2A deubiquitinating enzymes (DUBs)

\begin{tabular}{|c|c|c|c|c|c|}
\hline DUB & Domain structure & Substrate & Interactors & Process & Ref. \\
\hline USP3 & ZnF-UBP, UCH & $\mathrm{H} 2 \mathrm{~A}, \mathrm{H} 2 \mathrm{~B}$ & n.d. & $\begin{array}{l}\text { DNA damage response; S- } \\
\text { phase progression }\end{array}$ & {$[17]$} \\
\hline USPI6/UbpM & ZnF-UBP, UCH & $\mathrm{H} 2 \mathrm{~A}$ & n.d. & $\begin{array}{l}\text { Transcription of HoxD 10; G2/ } \\
\text { M transition }\end{array}$ & {$[24,33]$} \\
\hline USP2I & $\mathrm{UCH}$ & $\mathrm{H} 2 \mathrm{~A}$ & n.d. & Transcription & {$[25]$} \\
\hline USP22 & ZnF-UBP, UCH & $\mathrm{H} 2 \mathrm{~A}, \mathrm{H} 2 \mathrm{~B}$ & SAGA complex & $\begin{array}{l}\text { Transcriptional coactivator } \\
\text { with Myc, AR, ER, GR; GI/S } \\
\text { transition }\end{array}$ & {$[28,29]$} \\
\hline 2A-DUB/KIAAI9I5/MYSMI & SANT, SWIRM, JAMM/MPN+ & $\mathrm{H} 2 \mathrm{~A}$ & p/CAF, Trip5/KIFII, Rbm I0 & $\begin{array}{l}\text { Transcriptional coactivator } \\
\text { with } A R\end{array}$ & {$[27]$} \\
\hline
\end{tabular}

Abbreviations: ZnF-UBP, Zinc Finger-Ubiquitin Binding Domain; UCH, Ubiquitin C Terminal Hydrolase domain; AR, Androgen Receptor; ER, Estrogen Receptor; GR, Growth hormone Receptor; 2A-DUB, H2A DeUBiquitinase; JAMM, JABI/MPN/Mov34 metalloenzyme domain; MPN+, Mprl, PadI N-terminal + domain; p/CAF, p300/CBP Associated Factor; n.d., not determined. 
Table 2: Mammalian H2A E3 ubiquitin ligases

\begin{tabular}{|c|c|c|c|c|c|}
\hline E3 ligase & Domain structure & Substrate & Interactors & Process & Ref. \\
\hline $\begin{array}{l}\text { Ring IA/RINGI, RingIB/ } \\
\text { RNF2 }\end{array}$ & RING & $\mathrm{H} 2 \mathrm{~A}$ & $\begin{array}{l}\mathrm{PRCl} \text {; E2F-6; FbxlI0/BcoR } \\
\text { complexes }\end{array}$ & $\begin{array}{l}\text { Repression of } \\
\text { transcription }\end{array}$ & {$[11-14,30-32,86,87]$} \\
\hline RNF8 & FHA, RING & $\mathrm{H} 2 \mathrm{~A} / \mathrm{H} 2 \mathrm{AX}$ & n.d. & $\begin{array}{l}\text { DNA damage response; } \\
\text { G2/M transition }\end{array}$ & {$[18,19,54,55,63,84,85]$} \\
\hline $\begin{array}{l}\text { 2A-HUB/KIAA0675/ } \\
\text { hRULI 38/DZIP3 }\end{array}$ & RING & $\mathrm{H} 2 \mathrm{~A}$ & $\mathrm{~N}-\mathrm{CoR}, \mathrm{HDACI}, \mathrm{HDAC} 3$ & $\begin{array}{l}\text { Repression of specific } \\
\text { chemokine genes }\end{array}$ & {$[40]$} \\
\hline
\end{tabular}

Abbreviations: PRCI, Polycomb Repressive Complex I; FbxlI0, F-box and leucine-rich repeat protein I0 (JHDIB); BcoR, BCL6 co-repressor; RNF8, Ring Finger protein 8; FHA, forkhead-associated phosphopeptide-binding domain; N-CoR, Nuclear receptor Co-Repressor; HDAC, Histone De-Acetylase; n.d., not determined.

\section{H2A DUBs: novel insights into uH2A-mediated transcription inhibition Ubp-M (USPI6)}

Extensive biochemical purification of a H2A de-ubiquitinating activity from HeLa cells, identified Ubp-M as the responsible enzyme [24]. In agreement, the in vitro activity of Ubp-M towards $\mathrm{uH} 2 \mathrm{~A}$ had been reported before [33]. By double chromatin immunoprecipitation experiments, in Ubp-M knockdown (KD) HeLa cells, Joo et al. showed increased $\mathrm{uH} 2 \mathrm{~A}$ levels at the promotor of a homeotic (Hox) gene, HoxD10, accompanied by gene repression. Wildtype but not catalytic mutant Ubp-M could rescue HoxD10 expression [24]. The in vivo relevance of Ubp-M mediated Hox gene activation was suggested by the observation that injection of Ubp-M antibodies in Xenopus embryos led to deregulation of HoxD10 expression and defects in posterior development. This anterior-posterior transformation phenotype is consistent with a Polycombantagonistic function (reviewed in [15]). Altogether, these data suggest that Ubp-M counteracts the role of Polycomb proteins in Hox gene repression through H2A deubiquitination.

\section{USP2I}

Nakagawa and colleagues used liver regeneration as a model system [25]. Examining gene expression changes after hepatectomy, the authors found that USP21 is upregulated. As liver regeneration is associated with a decrease in global uH2A, USP21 was hypothesized to target H2A for deubiquitination during this process. USP21 DUB activity towards H2A was confirmed in vitro. Evidence for a repressive role of $\mathrm{uH} 2 \mathrm{~A}$ came from in vitro transcription assays, in which chromatin templates reconstituted with $\mathrm{uH} 2 \mathrm{~A}$ inhibited transcript formation. In vivo, overexpression of USP21 in liver correlated with low levels of $\mathrm{uH} 2 \mathrm{~A}$ and increased expression of a gene, Serpina6, which is downregulated during normal hepatocyte regeneration.

\section{A-DUB}

2A-DUB was identified as a positive regulator of androgen receptor (AR) transactivation activity on a reporter gene and it was characterized as a histone H2A DUB in vitro and in vivo [27]. 2A-DUB is unique among the $\mathrm{uH} 2 \mathrm{~A}$ proteases identified so far, harboring a JAMM/MPN+ domain, and SANT and SWIRM domains, frequently found in DNA and chromatin-associated proteins [26,27]. Knockdown of $2 \mathrm{~A}$-DUB resulted in the attenuation of dihydrotestosterone-induced gene expression in a prostate cancer cell line, confirming an AR-coregulatory role for the endogenous protein. 2A-DUB is associated with the p/CAF histone acetyl transferase. This led to the investigation of a possible link between histone acetylation and H2A deubiquitination. It was found that histone acetylation (in vitro) and $\mathrm{p} / \mathrm{CAF}$ (in vivo) facilitated H2A de-ubiquitination (Figure 1A). However, p/CAF did not apparently affect 2A-DUB binding with the promoter, suggesting that $2 \mathrm{~A}-\mathrm{DUB}$ is not directly recruited by $\mathrm{p} / \mathrm{CAF}$. Instead, $\mathrm{p} / \mathrm{CAF}$ dependent acetylation may, directly or indirectly, influence 2A-DUB activity.

\section{USP22}

$\mathrm{H} 2 \mathrm{~B}$ is the only histone known to be ubiquitinated in $S$. cerevisiae [34]. Monoubiquitinated $\mathrm{H} 2 \mathrm{~B}(\mathrm{uH} 2 \mathrm{~B})$ is highly dynamic and sequential ubiquitination and deubiquitination are required for efficient transcription (reviewed in [10]). A DUB capable of de-ubiquitinating H2B, Ubp8, is present in the yeast SAGA coactivator complex. Two recent papers show that the mammalian counterpart of the SAGA complex contains an Ubp8 homolog, the DUB USP22 [28,29], which is also conserved in Drosophila [35]. In addition to $\mathrm{H} 2 \mathrm{~B}$, USP22 de-ubiquitinates $\mathrm{H} 2 \mathrm{~A}$ in vitro [29]. As for Ubp8, an activating role of USP22 has been reported. Recruitment of the SAGA complex to target genes is known to be dependent on sequence specific transcription factors [36,37]. Accordingly, Zhang and colleagues showed that USP22 was recruited to myc target genes in a myc-dependent fashion [28].

\section{Does uH2A affect specific steps of transcription?}

RNA polymerase II- mediated transcription can be subdivided in three phases: initiation, elongation and termination. These phases are associated with distinct histone modifications as well as specific phosphorylation patterns of the heptad repeats of the C-terminal domain (CTD) of 


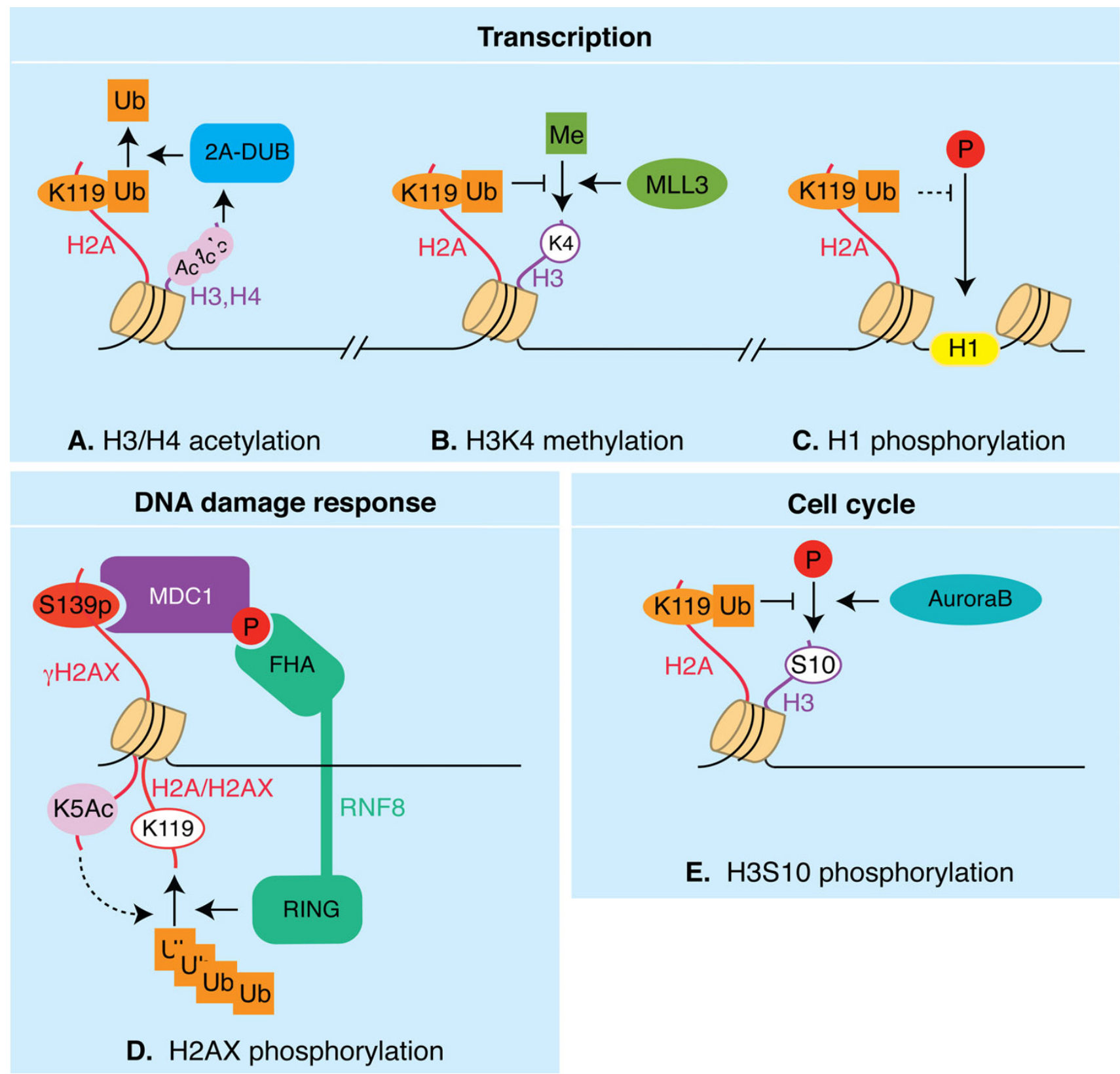

Figure I

Crosstalk between monoubiquitinated H2A (uH2A) and other histone modifications. Functional implications in transcription regulation (A-C), DNA damage response (D) and cell cycle progression (E) are illustrated. A. H3/H4 acetylation stimulates de-ubiquitination of $\mathrm{uH} 2 \mathrm{~A}$ by $2 \mathrm{~A}$-DUB in vitro, linking these modifications in the regulation of transcription. $\mathbf{B}$. $\mathrm{uH} 2 \mathrm{~A}$ prevents $\mathrm{H} 3 \mathrm{~K} 4$ methylation by MLL3 in vitro. This is possibly one of the mechanisms by which $\mathrm{uH} 2 \mathrm{~A}$ negatively affects transcription initiation. C. Elevated global levels of $\mathrm{uH} 2 \mathrm{~A}$ correlate with low phosphorylation of linker histone $\mathrm{HI}$, as observed upon knockdown of one of the H2A DUBs, 2A-DUB. Phosphorylation of HI is thought to favor enhanced chromatin dissociation of this histone. $\mathrm{uH} 2 \mathrm{~A}$ might, by promoting/stabilizing $\mathrm{HI}$ association with the nucleosome, diminish chromatin dynamics, thereby negatively affecting transcription. D. Histone phosphorylation and ubiquitination synergize in DNA damage signaling upon ionizing radiation (IR). Upon IR, phosphorylation of $\mathrm{H} 2 \mathrm{AX}$ leads to recruitment and phosphorylation of MDCI. Phosphorylated MDCI recruits RNF8 through its FHA domain. RNF8 subsequently polyubiquitinates H2A and H2AX. Also, TIP60dependent acetylation of $\mathrm{H} 2 \mathrm{AX}$ on $\mathrm{K} 5$ favors $\mathrm{H} 2 \mathrm{AX}$ polyubiquitination upon IR. E. uH2A inhibits $\mathrm{H} 3 \mathrm{SIO}$ phosphorylation by AuroraB kinase in vitro, providing a potential mechanism for regulation of G2/M transition in vivo. The labels "Ub", "Ac", "Me" and "P" refer to monoubiquitination, acetylation, di- and trimethylation, and phosphorylation respectively. 
the largest subunit of RNA polymerase II. Initiation is associated with $\mathrm{H} 3 \mathrm{~K} 4 \mathrm{di}$ - and trimethylation and CTD serine 5 phosphorylation (s5pCTD), while H3K36 trimethylation and CTD serine 2 phosphorylation (s2pCTD) correlate with elongation [38]. In vitro and in vivo approaches were undertaken to address if uH2A affects transcription initiation or elongation.

First, $\mathrm{uH} 2 \mathrm{~A}$ engagement in the initiation step of transcription is supported by in vitro studies by Nakagawa and colleagues [25]. GAL4-VP16 driven transcription was assayed on reconstituted chromatin templates using Drosophila nuclear extracts as a source of RNA polymerase II. As previously mentioned, $\mathrm{uH} 2 \mathrm{~A}$ inhibited transcription if the chromatin template was assembled before addition of the RNA polymerase. On similarly reconstituted chromatin templates, the authors showed that $\mathrm{uH} 2 \mathrm{~A}$ prevents $\mathrm{H} 3 \mathrm{~K} 4$ di- and trimethylation by the methyltransferase MLL3, and that USP21-mediated deubiquitination could relieve this inhibition (Figure 1B). Importantly, chromatin assembled with a specific mutant of histone H3 (H3K4R), allowed initiation despite the presence of $\mathrm{uH} 2 \mathrm{~A}$. Under these conditions, elongation occurred normally, suggesting that $\mathrm{uH} 2 \mathrm{~A}$ does not inhibit transcription per se, but that it might rather act by preventing H3K4 methylation, and thereby transcription initiation (Figure 2A).

In vivo support for this conclusion came from the study of Zhu et al. on 2A-DUB [27]. Expression of the PSA gene is induced upon stimulation of the AR. The authors examined chromatin changes at the PSA promoter, upon AR activation, through detailed ChIP experiments. AR activation resulted in a decrease of $\mathrm{uH} 2 \mathrm{~A}$ accompanied by increased levels of S5PCTD at the promoter and, therefore, increased transcription initiation. All these events were 2A-DUB dependent. Although the levels of H3K4Me were not examined, this study suggests that $\mathrm{uH} 2 \mathrm{~A}$ limits initiation in vivo as well.

Second, the link between $\mathrm{uH} 2 \mathrm{~A}$ and transcription elongation was examined in two recent papers on H2A E3 ligases, Ring1A/B and 2A-HUB [39,40].

Stock and colleagues examined chromatin changes at genes that are derepressed upon conditional deletion of Ring1 A and B and global loss of H2A monoubiquitination in mouse ES cells [39]. The promoters of these genes have been shown to associate with histone marks characteristic of both active (H3K4Me) and inactive (H3K27Me, $\mathrm{uH} 2 \mathrm{~A}$ ) chromatin and are therefore referred to as bivalent $[39,41,42]$, reviewed in [43]. Stock et al. showed that in wildtype cells, low-level transcription of the 5 ' region of the coding region of these genes was detectable. This result indicates that transcription was initiated, despite the presence of Ring1A/B and $\mathrm{uH} 2 \mathrm{~A}$ (Figure 2B). Indeed, at these promoters, S5pCTD RNA polymerase was present at levels comparable to actively transcribed genes. Given that RNA polymerase II was shown to associate with regions downstream of the promoter upon Ring1A/B deletion, the data support a model in which Ring1Bdependent $\mathrm{uH} 2 \mathrm{~A}$ hinders transcription at the stage of elongation (Figure 2C).

The involvement of $\mathrm{uH} 2 \mathrm{~A}$ in transcriptional events downstream of initiation is further supported by the characterization of a novel RING-type E3 ligase for H2A, 2A-HUB [40] (Table 2). Knockdown of 2A-HUB stimulates elongation but not initiation of transcription of one of its target genes, RANTES. $\mathrm{uH} 2 \mathrm{~A}$ is mainly present at the promoter of RANTES, as opposed to its distribution over both promoter and exonic regions at bivalent genes. As a consequence, in the case of RANTES, $\mathrm{uH} 2 \mathrm{~A}$ might regulate the transition of initiation to elongation, a process referred to as promoter escape.

In conclusion, it is still unclear at which stage $\mathrm{uH} 2 \mathrm{~A}$ affects the transcription cycle. It is of note that current data have been obtained in different in vivo and in vitro systems. For example, uH2A inhibits $\mathrm{H} 3 \mathrm{~K} 4$ methylation in vitro, whereas these marks, by definition, coexist at bivalent promoters in ES cells in vivo. This suggest that the strict inhibition of H3K4 methylation by $\mathrm{uH} 2 \mathrm{~A}$ observed in vitro is somehow circumvented at bivalent promoters in vivo, allowing initiation. If this interpretation holds true, it would predict that there might be different categories of target genes, regulated by dedicated mechanisms. In addition, we can envisage that, in vivo, $\mathrm{uH} 2 \mathrm{~A}$ may act as a "landing platform" for recruitment of, yet to be isolated, regulatory proteins containing ubiquitin binding domains (Figure 2C). The identification of such proteins will be pivotal to the understanding of uH2A-mediated regulation. Finally, it cannot be excluded that effects of the DUBs and E3 ligases targeting $\mathrm{H} 2 \mathrm{~A}$ on transcription phases are partially independent of their enzymatic function.

\section{Histone crosstalks and chromatin dynamics}

Work on the DUBs USP21 and 2A-DUB, suggest that uH2A may affect post-translational modifications on other histones, including H3K4 methylation (as discussed before) and $\mathrm{H} 1$ phosphorylation [25,27] (Figure 1B and 1C). Such "trans-histone" cross-talk between uH2B and H3 methylation has been well characterized [10]. We have previously discussed how $\mathrm{uH} 2 \mathrm{~A}$ negatively affects $\mathrm{H} 3 \mathrm{~K} 4$ methylation. Here we will report on the $\mathrm{uH} 2 \mathrm{~A}-\mathrm{H} 1$ interplay. Also, we will present findings pointing to a distinct mechanism, involving the histone chaperone FACT.

The C-terminal tail of H2A, containing the K119 ubiquitination site, can reach the linker histone $\mathrm{H} 1$ in nucleo- 


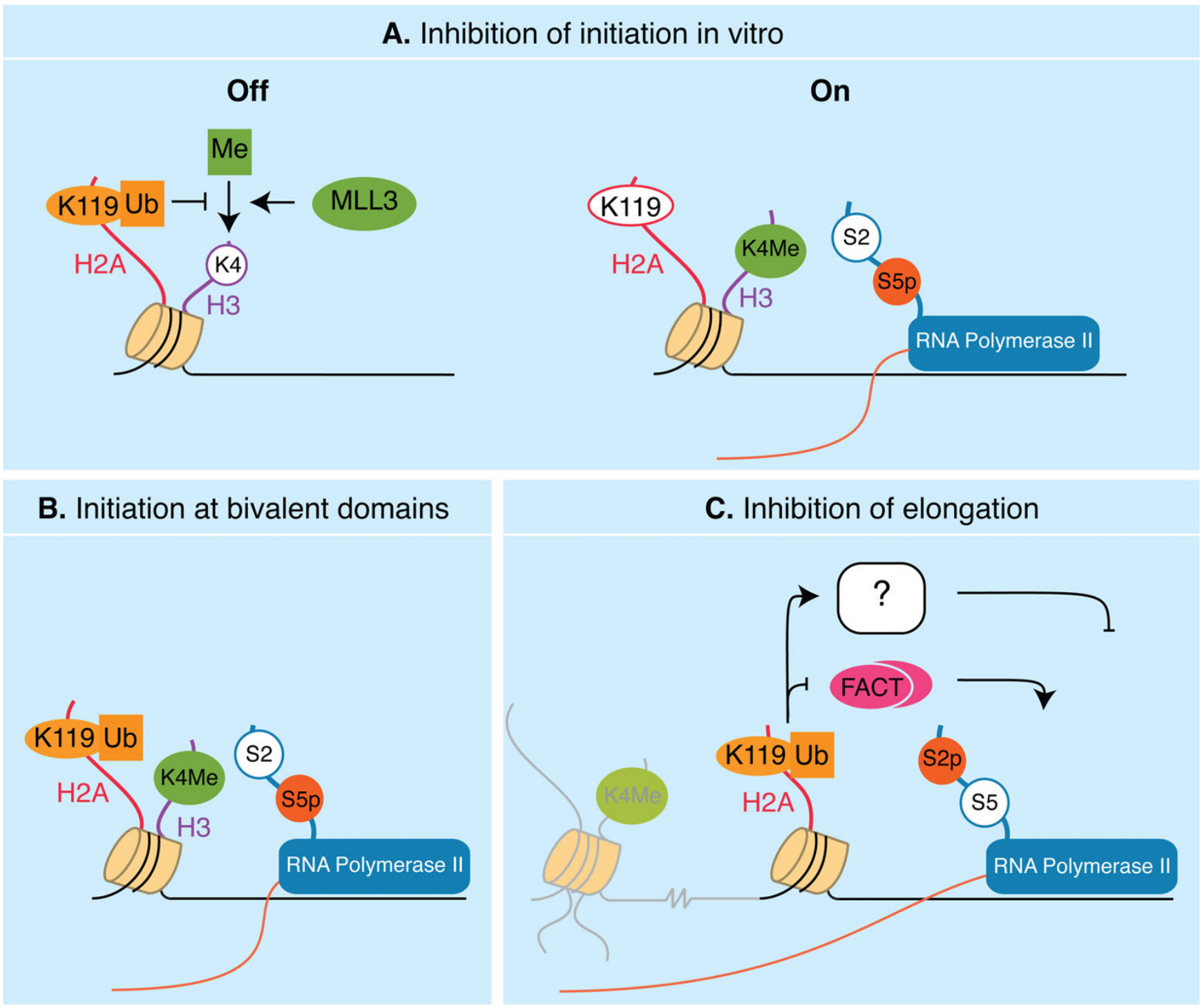

\section{Figure 2}

Models for regulation of transcription by monoubiquitinated H2A. A. uH2A inhibits RNA polymerase II initiation in vitro through a crosstalk with $\mathrm{H} 3 \mathrm{~K} 4$ methylation. uH2A prevents $\mathrm{H} 3 \mathrm{~K} 4$ methylation by the MLL3 histone methyltransferase. The enzymatic removal of ubiquitin from $\mathrm{H} 2 \mathrm{~A}$ by USP2I can positively influence $\mathrm{H} 3 \mathrm{~K} 4$ methylation by the methyltransferase. This would allow H3K4 methylation, which is a prerequisite for initiation of gene transcription. B. At bivalent promoters uH2A and $\mathrm{H} 3 \mathrm{~K} 4 \mathrm{Me}$ coexist. At these promoters, transcription initiation occurs despite the presence of uH2A. C. uH2A might inhibit transcription elongation or the transition from initiation to elongation by preventing association of the FACT elongation factor. In addition, uH2A might regulate elongation by recruiting inhibitory factors and/or affecting higher order chromatin association.

somes [4]. Immunoprecipitation of nucleosomes containing wt or its ubiquitination mutant, K119R, revealed that $\mathrm{H} 1$ preferentially associated with wt $\mathrm{H} 2 \mathrm{~A}$, suggesting that ubiquitination of H2A facilitates interaction with $\mathrm{H} 1$ [40]. In agreement, this has been shown in vitro [44]. H1 can be phosphorylated: a modification linked to enhanced $\mathrm{H} 1$ dynamics and chromatin dissociation [45]. Zhou and colleagues reported that a global increase in $\mathrm{uH} 2 \mathrm{~A}$, in 2A-DUB knock down cells, was associated with a decrease in phosphorylated H1 [40]. Knockdown of Ring1B had the opposite effect. Altogether, these findings suggest that $\mathrm{uH} 2 \mathrm{~A}$ hinders $\mathrm{H} 1$ eviction from chromatin, which is generally associated with an open chromatin conformation favorable to transcription (Figure 1C). 
Finally, a functional link between $\mathrm{uH} 2 \mathrm{~A}$ and the histone chaperone FACT (FAcilitates Chromatin Transcription) has been proposed [40]. The FACT complex has been shown to facilitate elongation, presumably by removal of $\mathrm{H} 2 \mathrm{~A} / \mathrm{H} 2 \mathrm{~B}$ dimers, thereby enabling RNA polymerase II movement through chromatin [46]. Chromatin association of FACT at the RANTES gene is stimulated by 2AHUB knockdown, with concomitant decrease in uH2A. Biochemically, it was shown that FACT associates mostly with non-ubiquitinated $\mathrm{H} 2 \mathrm{~A}$. A possible conclusion is that $\mathrm{uH} 2 \mathrm{~A}$ prevents FACT association. H2A deubiquitination would allow FACT to bind and to promote elongation. More detailed biochemical analysis is required to shed light on the mechanistic implications of uH2A-FACT interplay. An important implication of the 2A-DUB and 2A-HUB studies from the Rosenfeld lab is that ubiquitination of H2A may impact on nucleosome dynamics (as also discussed in the section on the DNA damage response), as well as on higher order chromatin structure.

In summary, the discussed studies highlight a positive role of H2A DUBs in gene expression. In addition, albeit with some redundancy [27-29], it seems that Ubp-M, USP21, USP22 and 2A-DUB participate in the regulation of specific transcriptional programs (Table 1). To understand how DUBs regulate transcription and how specific their activities are, important questions are i) where, along the chromosomes, do these enzymes bind and ii) which genes do they regulate. Gene expression profiles and genome-wide identification of the in vivo DNA binding sites of the DUBs (by ChIP on ChIP, Chip-Seq or DamID techniques) will be needed and will require extensive effort in the next years. Because of the difficulty in developing highly specific antibodies to $\mathrm{uH} 2 \mathrm{~A}$, an additional challenge will be to map the chromosomal regions containing uH2A. Finally, integration of these data with available genome-wide chromatin association data on histone modifications and crucial chromatin modifiers, including histone E3 ligases, methyltransferases, demethylases and remodeling enzymes, will likely lead to further insight into the intricate cross talk between histone modifications.

\section{uH2A: a marker for DNA damage?}

Genome integrity is maintained by the functional interplay between DNA repair processes and DNA damage checkpoint pathways, responsible for arresting the cell cycle to allow faithful repair [47]. Histone modifications play a crucial role both in DNA damage response (DDR) as well as DNA repair. They can act by i) facilitating DDR signaling or ii) influencing chromatin folding/organization. This second mode is mainly achieved by controlling the binding of effector proteins, among which chromatin remodeling factors, capable of altering histone-DNA contacts [48].
Evidence is accumulating that histone ubiquitination is part of the response to DNA damage. Studies in S. cerevisiae suggest a role for ubiquitinated $\mathrm{H} 2 \mathrm{~B}$ in checkpoint activation upon UV challenge [49] and in the formation of DNA double-strand breaks (DSBs) at some chromosomal loci during meiosis [50]. In mammalian cells, increased monoubiquitination of $\mathrm{H} 2 \mathrm{~A}, \mathrm{H} 3$, and $\mathrm{H} 4$ was shown upon UV irradiation [16,21,51]; reviewed in [52]. The recent characterization of two novel histone modifiers, the DUB USP3 and the E3/E2 ligase complex RNF8Ubc13, supports a broader role of $\mathrm{uH} 2 \mathrm{~A}$ in genome maintenance [17-19,53-55]. Here we will discuss the involvement of $\mathrm{uH} 2 \mathrm{~A}$ in the response to ionizing radiation (IR) emerging from these studies.

IR induces the re-localization of DNA damage signaling/ repair factors into IRIF (IR-induced nuclear foci). Beside protein accumulation, IRIF reflect chromatin rearrangements and histone post-translational modification at double-stranded DNA breaks (DSBs) [56,57]. Phosphorylation of the histone $\mathrm{H} 2 \mathrm{~A}$ variant $\mathrm{H} 2 \mathrm{AX}(\gamma \mathrm{H} 2 \mathrm{AX})$ by ATM (ataxia telangiectasia mutated), ATR (ATM and Rad3-related), and DNA-PK (DNA-dependent protein kinase) checkpoint kinases is an early event in response to DNA damage and represents the most robust histone modification upon IR [47]. $\gamma \mathrm{H} 2 \mathrm{AX}$ is instrumental for efficient accumulation and retention of several mediators/ repair factors, including MDC1, BRCA1, 53BP1 and ATM, at the chromatin surrounding the lesion $[58,59]$.

Several ubiquitination events take place at DSBs repair sites, as illustrated by the local accumulation of ubiquitinated substrates at IRIF [53,60-62]. However, only recently, immunofluorescence studies, with an anti-uH2A antibody, detected accumulation of $\mathrm{uH} 2 \mathrm{~A}$ at $\gamma \mathrm{H} 2 \mathrm{AX}$-containing nuclear foci early upon global IR as well as local, laser-mediated microirradiation $[17,19]$. Which species of ubiquitinated $\mathrm{H} 2 \mathrm{~A}$ accumulate at DSBs? Immunopurification of endogenous or ectopically expressed $\mathrm{H} 2 \mathrm{~A}$ or H2AX revealed an increase in oligo and poly-ubiquitinated species in cells exposed to high IR doses [18-20,53]. Huen et al. showed that H2AX was predominantly di-ubiquitinated upon IR. Notably, H2AX di-ubiquitination was dependent on its S139 phosphorylation site, suggesting that phosphorylation is a prerequisite for ubiquitination [18]. As to the ubiquitination site, it is still unclear whether in addition to the canonical lysine 119, ubiquitination of other lysines may participate in the DSB response $[18,20]$. These studies suggest that IR-induced ubiquitin marks on $\mathrm{H} 2 \mathrm{~A} / \mathrm{H} 2 \mathrm{AX}$ comprise a variety of ubiquitinated species, which differ from the steady state uH2A. 


\section{How is the histone ubiquitin mark set during the IR- response?}

Four independent studies recently identified RNF8 as the E3 ligase responsible for $\mathrm{H} 2 \mathrm{~A} / \mathrm{H} 2 \mathrm{AX}$ ubiquitination in the response to DSBs $[18,19,54,55]$. RNF8 rapidly accumulates at DSBs upon IR, concomitantly with early IRIF markers, namely $\gamma \mathrm{H} 2 \mathrm{AX}$, ATM, the MRN complex, and the mediator protein MDC1 [19]. The presence of a phosphothreonyl-binding FHA domain together with a RING finger domain enable RNF8 to link phosphorylation with ubiquitination signaling at IRIFs (Figure 1D). The data presented by the four laboratories are consistent with a signaling cascade starting from phosphorylation of H2AX by ATM (Figure 3). This step is well known and allows direct recruitment of MDC1 and its subsequent phosphorylation by ATM [59]. Through its FHA domain, RNF8 can in turn bind to phospho-MDC1 at DSBs, where it catalyzes polyubiquitination events, among which $\mathrm{H} 2 \mathrm{~A}$ and H2AX ubiquitination (Figure 3A). At IRIF, RNF8 likely acts in concert with the ubiquitin conjugating enzyme Ubc13, a previously reported interactor of RNF8 [18,5355,63]. At last, RNF8-Ubc13-dependent ubiquitination is required for recruitment and retention of BRCA1 and 53BP1 at DSBs $[18,19,54,55]$ (Figure 3B). Besides histone ubiquitination, ubiquitin signaling at IRIF likely comprises a complex variety of ubiquitination events, as also suggested by the partial requirement of a second E3 ligase activity, BRCA1, for efficient ubiquitin accumulation $[60,62]$. These may include amplification of the ubiquitination signal on histones or other substrates, as well as autoubiquitination of the E3 enzymes as autoregulatory mechanism $[64,65]$. In agreement, both RNF8 and BRCA1 can promote auto-ubiquitination and ubiquitination of histones in vitro $[19,63,66,67]$.

These studies revealed an exciting link between ATM signaling and ubiquitination of histone H2A and H2AX at double strand breaks. If $\mathrm{uH} 2 \mathrm{~A}$ is directly involved in recruitment of DDR factors at IRIF remains to be established.

\section{Mechanisms of uH2A-mediated DDR}

The ubiquitin-interacting-motif (UIM)-containing protein Rap80 is a good candidate for fulfilling a ubiquitin receptor function at IRIF. Rap80 was initially shown to recruit the Rap80-ccd98/abraxas-BRCA1 complex to ubiquitin-conjugates at DSBs $[61,68,69]$ (Figure 3B). More recently, it was demonstrated that accumulation of Rap80 at IRIF is dependent on functional RNF8-Ubc13 proteins $[18,19,54,55]$. In vitro and in vivo Rap80 displays preferential binding to lysine63-isopeptide-linked tetraubiquitin polymers, and to a lesser extent to K6-linked chains [61]. Importantly, Rap80 ubiquitin binding properties fit well with the findings that i) chain formation through lysine 63 has been previously shown to regulate, among others,

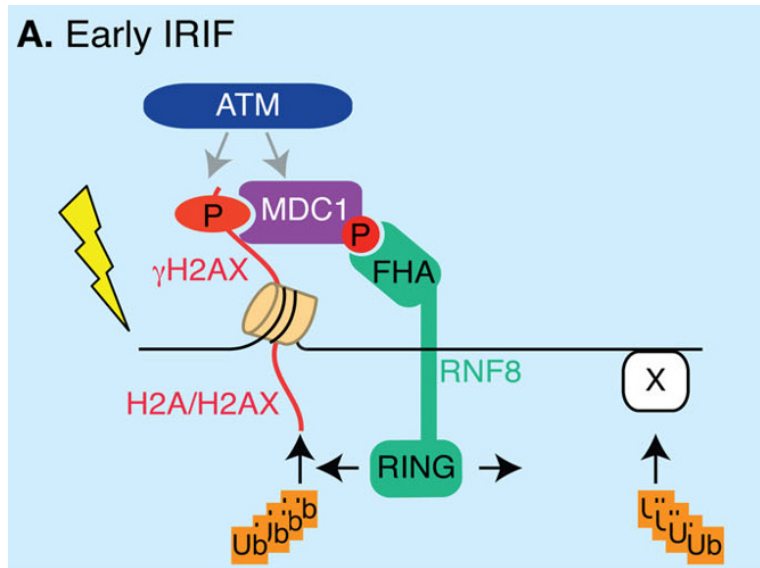

B. Late IRIF

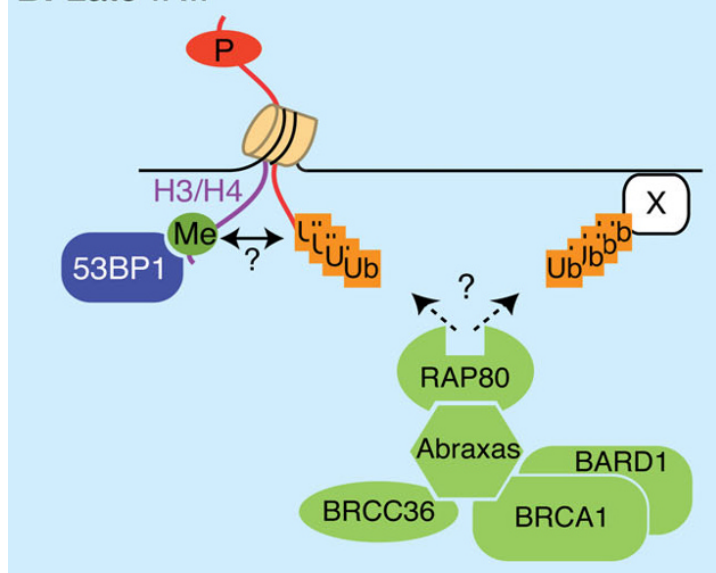

C. IRIF disassembly

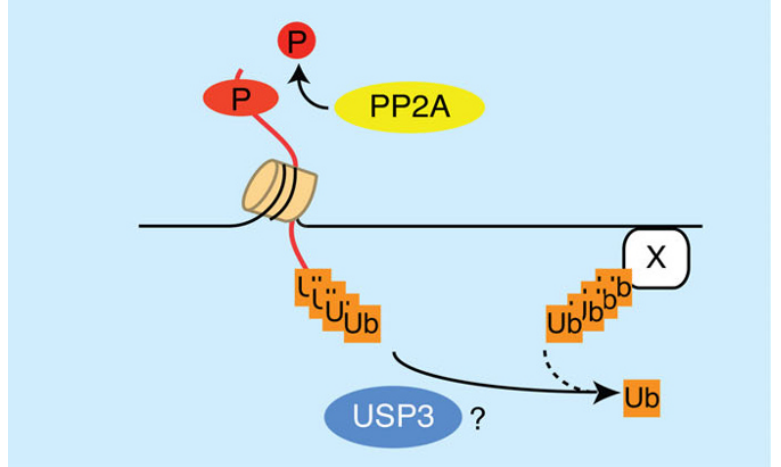

\section{Figure 3}

Signaling network at lonizing Radiation Induced Nuclear Foci (IRIF). A. Early after IR, damaged DNA triggers ATM activation, which consequently phosphorylates $\mathrm{H} 2 \mathrm{AX}$ near the break sites and $\mathrm{MDCl}$. RNF8 is recruited to IRIF through binding to phosphorylated MDCI. RNF8 locally ubiquitinates H2A, H2AX and possibly other yet unidentified proteins (' $X$ '). B. RNF8-dependent ubiquitin conjugation is required for recruitment of 53BPI and BRCAI. BRCAI is present in a protein complex containing BARDI, Abraxas/CCDC98, BRCC36 and RAP80. Ubiquitin binding by RAP80 is required for BRCAI recruitment. However, the nature of the ubiquitinated substrate RAP80 binds to (histones or other proteins), is still unclear. In addition to BRCAI, ubiquitination allows recruitment of 53BPI (which binds to methylated $\mathrm{H} 3 / \mathrm{H} 4$ ) through a yet unknown mechanism. C. IRIF disassembly may involve dephosphorylation of $\gamma \mathrm{H} 2 \mathrm{AX}$ by PP2A. The DUB USP3 is a candidate to remove conjugated ubiquitin at IRIF. 
DNA repair processes [60], ii) ubiquitin foci at IRIF form most efficiently through K63-linked polyubiquitination [61] and iii) Ubc13 is the only E2 able to catalyze polyubiquitination through $\mathrm{K} 63$ [70], and it is an E2 partner for RNF8 [63]. Although these evidences are consistent with Rap80 linking RNF8-Ubc13 ubiquitylation at IRIF to the DDR mediator BRCA1, studies addressing the potential direct binding of Rap80 to ubiquitinated H2A/H2AX are still needed.

It is important to note that other mechanisms may exist through which $\mathrm{H} 2 \mathrm{~A}$ ubiquitination could affect DDR. One plausible possibility is that $\mathrm{uH} 2 \mathrm{~A} / \mathrm{H} 2 \mathrm{AX}$ may facilitate a more global alteration of the chromatin, known to occur at DSBs $[57,71]$, allowing exposure of other histone marks. This mechanism might be relevant for 53BP1 relocalization to IRIF, as suggested by the findings that 53BP1 binds to methylated histones $[72,73]$ and that its recruitment is independent from Rap $80[18,19,55,68]$. Interestingly, Ikura and colleagues reported enhanced mobility of $\mathrm{H} 2 \mathrm{AX}$ at sites of microirradiation and a rapid release of polyubiquitinated H2AX from the chromatin [20]. H2AX ubiquitination and histone release was dependent on TIP60 and on its acetylation target, H2AX K5 (Figure 1D). Drosophila Tip60 can acetylate H2Av (the Drosophila $\mathrm{H} 2 \mathrm{AX}$ ) and promotes its exchange with unphosphorylated H2Av [74]. This work suggests a mechanism by which ubiquitination might promote histone dynamics/ removal.

\section{Removal of uH2A mark at DSBs: a role for USP3?}

The mechanisms by which the chromatin post-translational modifications are cleared, the protein assemblies are disassembled, and the checkpoint is turned off after completion of repair is an intriguing open question. Work form our group recently showed that USP3, previously identified as a DUB [75], displays deubiquitination activity both towards $\mathrm{uH} 2 \mathrm{~A}$ as well as $\mathrm{uH} 2 \mathrm{~B}$ in vivo [17]. USP3 appears to be engaged in DDR in two majors ways: in the response to IR and during normal S-phase progression (as discussed below). Upon IR, IRIF containing uH2A, ubiquitin, and $\gamma \mathrm{H} 2 \mathrm{AX}$ persist in USP3 knockdown cells [17]. Previously published results demonstrated that dephosphorylation and removal of H2AX is needed for efficient repair and resumption of the cell cycle [76-78]. In agreement, USP3 knock down cells are significantly delayed in $\mathrm{G} 2 / \mathrm{M}$ transition. Together, these data suggest that removal of ubiquitination marks at the chromatin surrounding DSBs is necessary to coordinate IRIF disassembly, $\gamma \mathrm{H} 2 \mathrm{AX}$ dephosphorylation and cell cycle recovery (Figure 3C). Unlike in S. cerevisiae [77,78], dephosphorylation of H2AX by the phosphatase PP2A is thought to occur on the chromatin, given that this enzyme localizes to IRIF [76]. If and how USP3 crosstalks with PP2A, for example by affecting recruitment or activity of the latter, is currently unknown. Although USP3 seems to favor deubiquitination of substrates (among which $\mathrm{UH} 2 \mathrm{~A}$ ) at IRIF, we could not detect local accumulation of USP3 at those foci (unpublished results). This may be a consequence of the fact that USP3 rapidly releases its chromatin substrate upon catalysis as determined by Fluorescence recovery after photobleaching (FRAP) and co-immunoprecipitation [17]. Also, it is possible that USP3 DUB activity may be required 'off the chromatin" or may be indirect. Isolation of USP3 interacting partners and potential additional substrates, as well as addressing if and how USP3 is regulated, is needed to gain a better understanding of the molecular mechanism of USP3-mediated DDR.

A JAMM domain containing DUB, BRCC36, may also play a role at DSBs: it is part of the BRCA1 A complex (together with RAP80 and Abraxas), localizes to IRIF and positively regulates BRCA1/BARD1 E3 ligase $[55,61,79,80]$. However, BRCC36 role at IRIF is not clear and its activity towards ubiquitinated histones has not been investigated.

In summary, the discovery of novel E3 ligase (RNF8) and DUB activities (USP3) for H2A provides us with valuable tools to address ubiquitin-mediated signaling at the chromatin. We can envision several experimental approaches towards the elucidation of the molecular mechanism(s) of $\mathrm{uH} 2 \mathrm{~A} / \mathrm{uH} 2 \mathrm{AX}-\mathrm{mediated}$ DDR. These include: i) biochemical characterization of the E3 (RNF8, BRCA1) and DUB activities (USP3, others?) on nucleosomes; ii) identification of the IR-induced ubiquitination site(s) on $\mathrm{H} 2 \mathrm{~A} / \mathrm{H} 2 \mathrm{AX}$; iii) isolation of $\mathrm{uH} 2 \mathrm{~A} / \mathrm{uH} 2 \mathrm{AX}$ binding proteins; iv) definition of the extent of the ubiquitin mark around the DSB. Also, a proteomic approach towards the characterization of the complex mixture of ubiquitinated proteins and ubiquitin receptors at the chromatin will potentially reveal novel players in DDR.

\section{uH2A and cell cycle}

Histone modifications play a pivotal role in the regulation of chromatin packaging during cell cycle progression. During G0-G1/S transition, repressive histone marks need to be removed to allow expression of S-phase genes $[30,81]$. Genome-wide chromatin rearrangements occur in S-phase, in order to provide accessibility to the replication machinery and to restore the epigenetic landscape on the newly synthesized DNA (reviewed in [82]). Finally, chromatin condensation and decondensation is needed during mitosis and cell division (reviewed in [5]).

As most of histone marks, ubiquitination is cell cycle regulated. uH2A was initially reported to be reduced in resting (G0) and differentiated cells [22]. Later, Vassilev et al. described a monoclonal antibody able to recognize $\mathrm{uH} 2 \mathrm{~A}$. Using this antibody, the authors reported that nonproliferating cells displayed lower levels of uH2A than 
their proliferating counterparts. In addition, partial colocalization of $\mathrm{uH} 2 \mathrm{~A}$ with PCNA replication foci was detected, suggesting a role for $\mathrm{uH} 2 \mathrm{~A}$ in cellular proliferation/DNA replication [83]. Interestingly, a link between $\mathrm{uH} 2 \mathrm{~A}$ and (aberrant) cell growth is emerging also in vivo. Dynamic changes in $\mathrm{uH} 2 \mathrm{~A}$ were observed in a liver regeneration model and in primary prostate tumors compared to normal tissues [25,27]. In proliferating cells, $\mathrm{uH} 2 \mathrm{~A}$ is present throughout the cell cycle, but it is down-regulated during G2/M transition and is not present on condensed chromosomes $[23,24]$.

\section{H2A-DUBs: specific roles in cell cycle regulation?}

Among the DUBs targeting H2A, USP22, Ubp-M and USP3 have been connected to cell cycle progression. Consistently, knockdown of these enzymes resulted in growth impairment in different human cell lines, albeit in different ways: i) upon shRNA-mediated knock-down of USP22, both p53 deficient H1299 cells and normal human fibroblast accumulated in G1 [28]; ii) USP3depleted U2OS cells showed a strong delay in S-phase progression and a low mitotic index [17]; iii) stable Ubp$M$ knockdown in HeLa cells resulted in a decrease in the proportion of cells in G2/M [24]. The potential impact of the two other H2A DUBs, 2A-DUB and USP21, on cell cycle progression has not been investigated yet $[25,27]$.

As discussed before, $\mathrm{uH} 2 \mathrm{~A}$ is functionally linked to transcription regulation and DNA damage signaling pathways. Does uH2A affect cell proliferation through transcriptional regulation of cell cycle genes or DDR activation, or through direct mechanism(s)? The data suggest that both indirect and direct mechanisms may be relevant.

First, USP22 has been characterized as a transcriptional co-activator in the context of the SAGA complex (see also the previous paragraph on transcription) $[28,29]$. Consequently, it is possible that the USP22 inhibitory effect on G1/S transition is dependent on its transcriptional activity. In addition, USP22 is required for Myc-driven transcription and transformation. Given that USP22, as well its Drosophila homolog Nonstop, appear to regulate a large subset of genes, gene expression analysis and genetic studies will be required to identify the key USP22-target genes involved in cell cycle progression $[28,29,35]$.

Second, data by our group point to a distinct mechanism by which USP3 may affect cell cycle. S-phase delay in USP3-KD cells is accompanied by spontaneous $\gamma \mathrm{H} 2 \mathrm{AX}$ foci, accumulation of DNA breaks and full activation of an ATM- and ATR-mediated checkpoint response [17]. Specific phenotypes were observed upon USP3 KD, including i) reduced ability to incorporate $\mathrm{BrdU}$, witnessing impaired DNA synthesis, ii) the presence of singlestranded DNA coated by replication protein A (RPA), iii) activation of the ATR-Chk1 pathway. These features are consistent with USP3 KD cells undergoing replication stress and suggest that S-phase delay and G2/M arrest are intimately linked to DDR activation in these cells. Wheter USP3 acts directly affecting the DNA replication process/ machinery, or rather through uH2A-mediated DDR signaling, is presently the subject of investigation. Persistence of $\gamma \mathrm{H} 2 \mathrm{AX}$ and $\mathrm{uH} 2 \mathrm{~A}$ DNA damage foci in USP3 KD cells upon thymidine-induced replication stress, as well as upon exogenous DNA damage (as discussed before), supports the participation of USP3 in ubiquitin ( $\mathrm{uH} 2 \mathrm{~A})$ mediated signaling (F. Nicassio and E. Citterio unpublished results). Finally, the observation that $\gamma \mathrm{H} 2 \mathrm{AX}$ foci, in USP3-depleted cells, coincide with the onset of S-phase suggests that DNA replication is required for DDR activation (F. Nicassio and E. Citterio unpublished results). Investigating how USP3 influences replication dynamics will possibly contribute to the understanding of USP3/ $\mathrm{uH} 2 \mathrm{~A}$ role at replication forks and its functional interplay with the S-phase checkpoint.

Third, H2A is globally de-ubiquitinated in the G2/M transition, which correlates with phosphorylation of $\mathrm{H} 3$ at S10, a hallmark of mitosis [24]. Interestingly, Joo et al. showed that Ubp-M is required for mitotic H2A de-ubiquitination and that knockdown of UbpM results in G2/M delay. In addition, in vitro experiments using reconstituted nucleosomes reveal that $\mathrm{uH} 2 \mathrm{~A}$ inhibits $\mathrm{H} 3$ phosphorylation on serine 10 by AuroraB, at least in part by preventing the binding of the kinase to nucleosomes (Figure 1E). Deubiquitination of H2A by UbpM relieves the inhibition of AuroraB. Since H3S10 phosphorylation by AuroraB is needed for chromosome condensation, these in vitro results put forward the exciting possibility that Ubp-Mmediated H2A deubiquitination may affect G2/M transition through a direct mechanism. Further investigation will reveal if this is true in vivo.

Intriguingly, despite targeting the same substrate, H2A DUBs display specificity in their roles in cell cycle regulation. It is unknown whether this specificity is due to additional protein targets, besides $\mathrm{H} 2 \mathrm{~A}$, or to other mechanisms. Therefore, it will be interesting to assess if different H2A DUBs can rescue each other defects in cell cycle progression.

Finally, the H2A E3 ligases Ring1B and RNF8 are clearly implicated in cell proliferation. Work by different groups support a functional role for RNF8 in mitosis, showing its requirement for mitotic exit $[84,85]$. Whether the effects of RNF8 on mitosis are dependent on ubiquitination of $\mathrm{H} 2 \mathrm{~A}$ remains to be investigated. As to Ring1 $\mathrm{B}$, its deletion in mice is associated with gastrulation arrest and embryonic lethality [86]. Given that Ring1B deletion strongly impact on expression of its target genes, it is difficult to 
distinguish between direct and indirect effects of Ring1B on cell cycle progression [86,87]. Knockdown of Ring1B results in cell cycle arrest in U2OS cells [11]. It will be interesting to analyze this phenotype in more detail to assess which phase of the cell cycle is affected.

\section{Concluding remarks}

Overall, the discussed data show that uH2A impacts on several important aspects of cellular physiology. Although recent work provides crucial insights, we are just starting to decipher the role of $\mathrm{uH} 2 \mathrm{~A}$. Intriguingly, despite the common substrate, individual H2A DUBs seem to exhibit distinct functional roles. In this regard, we will put forward key questions concerning regulation of activity, recruitment and substrate specificity, whose addressing is predicted to greatly advance our knowledge of how DUBs impact on the pleotropic function of H2A.

How is the activity of the H2A DUBs regulated? Interaction with regulatory, non catalytic protein subunits and posttranslational modifications have been shown to regulate DUB activity, including activity of USP7, USP1 and USP28 [88-93]. Similar mechanisms may apply to the H2A DUBs. USP22 displays in vitro H2A DUB activity only in the context of SAGA, suggesting that other subunits of the complex are important for the regulation of its activity $[27,29]$. Phosphorylation of UbpM (USP16) and monoubiquitination of 2A-DUB have been reported [24,27,33]. However, the functional significance of these observations remains to be elucidated.

How are H2A DUBs recruited to specific chromosomal loci? As discussed before, in the case of USP22 and 2ADUB, local recruitment to their respective target genes has been shown to depend on components of the protein complexes they reside in (SAGA for USP22), as well as on specific transcription factors [27-29]. The finding that two DUBs, 2A-DUB and USP22 associate with HATs suggests an important functional interplay between these classes of enzymes. Biochemical purification of the other DUBs (complexes) has yet to be performed.

Do H2A DUBs target additional substrates for deubiquitination? USP3 and USP22 are capable of deubiquitinating $\mathrm{H} 2 \mathrm{~B}$, in addition to H2A $[17,28,29,35]$. Moreover, USP22 may be required for deubiquitination of additional nonhistone proteins, as suggested by accumulation of other ubiquitinated proteins upon loss-of-function of its Drosophila homolog [94]. The ability to target more than one substrate is not unprecedented among DUBs [90,93]. The identification of putative additional key substrates is essential for a better understanding of the function of the H2A DUBs.
Finally, multiple observations suggest that H2A (de)ubiquitination influences chromatin dynamics, in part through the action of histone chaperones such as FACT and Tip $60[20,27,40]$. This may prove a common mode to facilitate chromatin reorganization during transcription, DDR and DNA replication, explaining the diversity of processes that $\mathrm{H} 2 \mathrm{~A}$ DUBs and $\mathrm{uH} 2 \mathrm{~A}$ play a role in. It will be important to examine the effect of ubiquitination of $\mathrm{H} 2 \mathrm{~A}$ on histone mobility and to define how uH2A impacts on the activities of chromatin remodeling complexes/histone chaperones. The identification of the DUBs and E3 ligases described in this review, as well as potential novel ones will undoubtedly greatly facilitate such analysis.

\section{Competing interests}

The authors declare that they have no competing interests.

\section{Authors' contributions}

JHAV, FN and EC wrote the paper. JHAV designed the figures. All authors contributed to the ideas elaborated in the paper and read and approved the final manuscript.

\section{Acknowledgements}

This work was supported by the Dutch Cancer Society (KWF) to EC and MvL, by AIRC (Italian Association for Cancer Research), the European Community (VI Framework), the Italian Ministries of Health, and of Education and University, the Ferrari Foundation, the Monzino Foundation and the CARIPLO Foundation to PPDF, and by the Ernst Schering Foundation to JHAV.

\section{References}

I. Pickart CM, Eddins MJ: Ubiquitin: structures, functions, mechanisms. Biochim Biophys Acta 2004, 1695:55-72.

2. Woelk T, Sigismund S, Penengo L, Polo S: The ubiquitination code: a signalling problem. Cell Div 2007, 2: I I.

3. Hicke L, Schubert HL, Hill CP: Ubiquitin-binding domains. Nat Rev Mol Cell Biol 2005, 6:610-62I.

4. Luger K, Mader AW, Richmond RK, Sargent DF, Richmond TJ: Crystal structure of the nucleosome core particle at $2.8 \mathrm{~A}$ resolution. Nature 1997, 389:251-260.

5. Kouzarides T: Chromatin modifications and their function. Cell 2007, I 28:693-705.

6. Jenuwein T, Allis CD: Translating the histone code. Science 200I, 293: $1074-1080$.

7. Goldknopf IL, Taylor CW, Baum RM, Yeoman LC, Olson MO, Prestayko AW, Busch $\mathrm{H}$ : Isolation and characterization of protein A24, a "histone-like" non-histone chromosomal protein. J Biol Chem 1975, 250:7182-7187.

8. Thorne AW, Sautiere P, Briand G, Crane-Robinson C: The structure of ubiquitinated histone H2B. EMBO J 1987, 6: 1005-1010.

9. Zhang $Y$ : Transcriptional regulation by histone ubiquitination and deubiquitination. Genes Dev 2003, I 7:2733-2740.

10. Shilatifard A: Chromatin modifications by methylation and ubiquitination: implications in the regulation of gene expression. Annu Rev Biochem 2006, 75:243-269.

II. Wang H, Wang L, Erdjument-Bromage H, Vidal M, Tempst P, Jones $\mathrm{RS}$, Zhang $\mathrm{Y}$ : Role of histone H2A ubiquitination in Polycomb silencing. Nature 2004, 43 I:873-878.

12. de Napoles M, Mermoud JE, Wakao R, Tang YA, Endoh M, Appanah R, Nesterova TB, Silva J, Otte AP, Vidal M, Koseki H, Brockdorff N: Polycomb group proteins Ring I A/B link ubiquitylation of histone $\mathrm{H} 2 \mathrm{~A}$ to heritable gene silencing and $X$ inactivation. Dev Cell 2004, 7:663-676. 
13. Cao R, Tsukada Y, Y. Z: Role of Bmi-I and Ring I A in H2A ubiquitylation and hox gene silencing. Molecular Cell 2005, 20:845-854.

14. Buchwald G, van der Stoop P, Weichenrieder O, Perrakis A, van Lohuizen M, Sixma TK: Structure and E3-ligase activity of the Ring-Ring complex of polycomb proteins Bmil and Ring I b. Embo J 2006, 25:2465-2474.

15. Sparmann A, van Lohuizen M: Polycomb silencers control cell fate, development and cancer. Nat Rev Cancer 2006, 6:846-856

16. Bergink S, Salomons FA, Hoogstraten D, Groothuis TA, de Waard H Wu J, Yuan L, Citterio E, Houtsmuller AB, Neefjes J, Hoeijmakers JH, Vermeulen W, Dantuma NP: DNA damage triggers nucleotide excision repair-dependent monoubiquitylation of histone H2A. Genes Dev 2006, 20:1343-1352.

17. Nicassio F, Corrado N, Vissers JH, Areces LB, Bergink S, Marteijn JA Geverts B, Houtsmuller AB, Vermeulen W, Di Fiore PP, Citterio E: Human USP3 Is a Chromatin Modifier Required for S Phase Progression and Genome Stability. Curr Biol 2007, I 7:1972-1977.

18. Huen MS, Grant R, Manke I, Minn K, Yu X, Yaffe MB, Chen J: RNF8 Transduces the DNA-Damage Signal via Histone Ubiquitylation and Checkpoint Protein Assembly. Cell 2007, | $31: 90|-9| 4$

19. Mailand N, Bekker-Jensen S, Faustrup H, Melander F, Bartek J, Lukas C, Lukas J: RNF8 Ubiquitylates Histones at DNA DoubleStrand Breaks and Promotes Assembly of Repair Proteins. Cell 2007, I 3 I:887-900

20. Ikura T, Tashiro S, Kakino A, Shima H, Jacob N, Amunugama R, Yoder K, Izumi S, Kuraoka I, Tanaka K, Kimura H, Ikura M, Nishikubo S, Ito T, Muto A, Miyagawa K, Takeda S, Fishel R, Igarashi K, Kamiya K: DNA damage-dependent acetylation and ubiquitination of H2AX enhances chromatin dynamics. Mol Cell Biol 2007, 27:7028-7040.

21. Kapetanaki MG, Guerrero-Santoro J, Bisi DC, Hsieh CL, Rapic-Otrin V, Levine AS: The DDB I-CUL4ADDB2 ubiquitin ligase is deficient in xeroderma pigmentosum group $E$ and targets histone H2A at UV-damaged DNA sites. Proc Natl Acad Sci U S A 2006, I 03:2588-2593.

22. Wunsch $A M$, Haas $A L$, Lough J: Synthesis and ubiquitination of histones during myogenesis. Dev Biol 1987, I I 9:85-93.

23. Mueller RD, Yasuda H, Hatch CL, Bonner WM, Bradbury EM: Identification of ubiquitinated histones $2 A$ and 2B in Physarum polycephalum. Disappearance of these proteins at metaphase and reappearance at anaphase. J Biol Chem 1985, 260:5147-5153.

24. Joo HY, Zhai L, Yang C, Nie S, Erdjument-Bromage H, Tempst $P$, Chang C, Wang $\mathrm{H}$ : Regulation of cell cycle progression and gene expression by H2A deubiquitination. Nature 2007, 449: $1068-1072$

25. Nakagawa T, Kajitani T, Togo S, Masuko N, Ohdan H, Hishikawa Y, Koji T, Matsuyama T, Ikura T, Muramatsu M, Ito T: Deubiquitylation of histone $\mathrm{H} 2 \mathrm{~A}$ activates transcriptional initiation via trans-histone cross-talk with H3K4 di- and trimethylation. Genes Dev 2008, 22:37-49.

26. Nijman SM, Luna-Vargas MP, Velds A, Brummelkamp TR, Dirac AM, Sixma TK, Bernards R: A genomic and functional inventory of deubiquitinating enzymes. Cell 2005, I 23:773-786.

27. Zhu P, Zhou W, Wang J, Puc J, Ohgi KA, Erdjument-Bromage $H$, Tempst P, Glass CK, Rosenfeld MG: A histone H2A deubiquitinase complex coordinating histone acetylation and $\mathrm{HI}$ dissociation in transcriptional regulation. Mol Cell 2007, 27:609-62I.

28. Zhang XY, Varthi M, Sykes SM, Phillips C, Warzecha C, Zhu W, Wyce A, Thorne AW, Berger SL, McMahon SB: The putative cancer stem cell marker USP22 is a subunit of the human SAGA complex required for activated transcription and cell-cycle progression. Mol Cell 2008, 29: I02-III.

29. Zhao Y, Lang G, Ito S, Bonnet J, Metzger E, Sawatsubashi S, Suzuki E, Le Guezennec X, Stunnenberg HG, Krasnov A, Georgieva SG, Schule R, Takeyama K, Kato S, Tora L, Devys D: A TFTC/STAGA module mediates histone $\mathrm{H} 2 \mathrm{~A}$ and $\mathrm{H} 2 \mathrm{~B}$ deubiquitination, coactivates nuclear receptors, and counteracts heterochromatin silencing. Mol Cell 2008, 29:92-101.

30. Ogawa H, Ishiguro K, Gaubatz S, Livingston DM, Nakatani Y: A complex with chromatin modifiers that occupies E2F- and Mycresponsive genes in $\mathbf{G 0}$ cells. Science 2002, 296: I | 32- I I 36.
3I. Sanchez C, Sanchez I, Demmers JA, Rodriguez P, Strouboulis J, Vidal $M$ : Proteomics analysis of Ring IB/Rnf 2 interactors identifies a novel complex with the FbxII0/Jhdm I B histone demethylase and the Bcl6 interacting corepressor. Mol Cell Proteomics 2007, 6:820-834

32. Gearhart MD, Corcoran CM, Wamstad JA, Bardwell VJ: Polycomb group and SCF ubiquitin ligases are found in a novel BCOR complex that is recruited to BCL6 targets. Mol Cell Biol 2006, 26:6880-6889.

33. Cai SY, Babbitt RW, Marchesi VT: A mutant deubiquitinating enzyme (Ubp-M) associates with mitotic chromosomes and blocks cell division. Proc Natl Acad Sci U S A 1999, 96:2828-2833.

34. Robzyk K, Recht J, Osley MA: Rad6-dependent ubiquitination of histone H2B in yeast. Science 2000, 287:50 I-504.

35. Weake VM, Lee KK, Guelman S, Lin CH, Seidel C, Abmayr SM, Workman JL: SAGA-mediated H2B deubiquitination controls the development of neuronal connectivity in the Drosophila visual system. Embo J 2008, 27:394-405.

36. Brown CE, Howe L, Sousa K, Alley SC, Carrozza MJ, Tan S, Workman JL: Recruitment of HAT complexes by direct activator interactions with the ATM-related Tral subunit. Science 200I, 292:2333-2337.

37. Park J, Kunjibettu S, McMahon SB, Cole MD: The ATM-related domain of TRRAP is required for histone acetyltransferase recruitment and Myc-dependent oncogenesis. Genes Dev 200I, I5:1619-1624.

38. Li B, Carey M, Workman JL: The role of chromatin during transcription. Cell 2007, I 28:707-719.

39. Stock JK, Giadrossi S, Casanova M, Brookes E, Vidal M, Koseki H, Brockdorff N, Fisher AG, Pombo A: Ring I-mediated ubiquitination of $\mathrm{H} 2 \mathrm{~A}$ restrains poised RNA polymerase II at bivalent genes in mouse ES cells. Nat Cell Biol 2007, 9:|428-|435.

40. Zhou W, Zhu P, Wang J, Pascual G, Ohgi KA, Lozach J, Glass CK, Rosenfeld MG: Histone H2A monoubiquitination represses transcription by inhibiting RNA polymerase II transcriptional elongation. Mol Cell 2008, 29:69-80.

41. Bernstein BE, Mikkelsen TS, Xie X, Kamal M, Huebert DJ, Cuff J, Fry B, Meissner A, Wernig M, Plath K, Jaenisch R, Wagschal A, Feil R, Schreiber SL, Lander ES: A bivalent chromatin structure marks key developmental genes in embryonic stem cells. Cell 2006 1 25:315-326.

42. Azuara V, Perry P, Sauer S, Spivakov M, Jorgensen HF, John RM, Gout M, Casanova M, Warnes G, Merkenschlager M, Fisher AG: Chromatin signatures of pluripotent cell lines. Nat Cell Biol 2006, 8:532-538.

43. Pietersen $A M$, van Lohuizen $M$ : Stem cell regulation by polycomb repressors: postponing commitment. Curr Opin Cell Biol 2008, 20:20I-207

44. Jason LJ, Finn RM, Lindsey G, Ausio J: Histone H2A ubiquitination does not preclude histone $\mathrm{HI}$ binding, but it facilitates its association with the nucleosome. I Biol Chem 2005, 280:4975-4982

45. Contreras A, Hale TK, Stenoien DL, Rosen JM, Mancini MA, Herrera RE: The dynamic mobility of histone $\mathrm{HI}$ is regulated by cyclin/CDK phosphorylation. Mol Cell Biol 2003, 23:8626-8636.

46. Reinberg D, Sims RJ III: de FACTo nucleosome dynamics. J Biol Chem 2006, 28 I:23297-2330I

47. Shiloh Y: ATM and related protein kinases: safeguarding genome integrity. Nat Rev Cancer 2003, 3:155-168.

48. Downs JA, Nussenzweig MC, Nussenzweig A: Chromatin dynamics and the preservation of genetic information. Nature 2007, 447:951-958

49. Giannattasio M, Lazzaro F, Plevani P, Muzi-Falconi M: The DNA damage checkpoint response requires histone $\mathrm{H} 2 \mathrm{~B}$ ubiquitination by Rad6-Brel and $\mathbf{H 3}$ methylation by Dot I. J Biol Chem 2005, 280:9879-9886.

50. Yamashita K, Shinohara M, Shinohara A: Rad6-Brel-mediated histone $\mathrm{H} 2 \mathrm{~B}$ ubiquitylation modulates the formation of doublestrand breaks during meiosis. Proc Natl Acad Sci U S A 2004, I 0 I: I | 380- | | 385.

5I. Wang H, Zhai L, Xu J, Joo HY, Jackson S, Erdjument-Bromage H, Tempst $\mathrm{P}$, Xiong $\mathrm{Y}$, Zhang $\mathrm{Y}$ : Histone $\mathrm{H3}$ and $\mathrm{H} 4$ ubiquitylation by the CUL4-DDB-ROCI ubiquitin ligase facilitates cellular response to DNA damage. Mol Cell 2006, 22:383-394. 
52. Bergink S, Jaspers NG, Vermeulen W: Regulation of UV-induced DNA damage response by ubiquitylation. DNA Repair (Amst) 2007, 6: $|23|-\mid 242$.

53. Zhao GY, Sonoda E, Barber LJ, Oka H, Murakawa Y, Yamada K, lkura T, Wang X, Kobayashi M, Yamamoto K, Boulton SJ, Takeda S: A critical role for the ubiquitin-conjugating enzyme Ubc 13 in initiating homologous recombination. Mol Cell 2007, 25:663-675.

54. Kolas NK, Chapman JR, Nakada S, Ylanko J, Chahwan R, Sweeney FD, Panier S, Mendez M, Wildenhain J, Thomson TM, Pelletier L, Jackson SP, Durocher D: Orchestration of the DNA-Damage Response by the RNF8 Ubiquitin Ligase. Science 2007, 3 I 8: 1637-1640.

55. Wang B, Elledge SJ: Ubcl3/Rnf8 ubiquitin ligases control foci formation of the Rap80/Abraxas/Brcal/Brcc36 complex in response to DNA damage. Proc Natl Acad Sci U S A 2007, 1 04:20759-20763.

56. Bekker-Jensen S, Lukas C, Kitagawa R, Melander F, Kastan MB, Bartek J, Lukas J: Spatial organization of the mammalian genome surveillance machinery in response to DNA strand breaks. J Cell Biol 2006, 173:195-206.

57. Kruhlak MJ, Celeste A, Dellaire G, Fernandez-Capetillo O, Muller WG, McNally JG, Bazett-Jones DP, Nussenzweig A: Changes in chromatin structure and mobility in living cells at sites of DNA double-strand breaks. / Cell Biol 2006, 172:823-834.

58. Celeste A, Fernandez-Capetillo O, Kruhlak MJ, Pilch DR, Staudt DW, Lee A, Bonner RF, Bonner WM, Nussenzweig A: Histone H2AX phosphorylation is dispensable for the initial recognition of DNA breaks. Nat Cell Biol 2003, 5:675-679.

59. Stucki M, Clapperton JA, Mohammad D, Yaffe MB, Smerdon SJ, Jackson SP: MDCI directly binds phosphorylated histone H2AX to regulate cellular responses to DNA double-strand breaks. Cell 2005, I 23:1213-1226.

60. Huang TT, D'Andrea AD: Regulation of DNA repair by ubiquitylation. Nat Rev Mol Cell Biol 2006, 7:323-334

6I. Sobhian B, Shao G, Lilli DR, Culhane AC, Moreau LA, Xia B, Livingston DM, Greenberg RA: RAP80 targets BRCAI to specific ubiquitin structures at DNA damage sites. Science 2007 316:1198-1202.

62. Polanowska J, Martin JS, Garcia-Muse T, Petalcorin MI, Boulton SJ: A conserved pathway to activate BRCAI-dependent ubiquitylation at DNA damage sites. Embo J 2006, 25:2178-2। 88.

63. Plans V, Scheper J, Soler M, Loukili N, Okano Y, Thomson TM: The RING finger protein RNF8 recruits UBCI3 for lysine 63 based self polyubiquitylation. / Cell Biochem 2006, 97:572-582.

64. Lorick KL, Jensen JP, Fang S, Ong AM, Hatakeyama S, Weissman AM: RING fingers mediate ubiquitin-conjugating enzyme (E2)dependent ubiquitination. Proc Natl Acad Sci U S A 1999, 96:11364-11369.

65. Woelk T, Oldrini B, Maspero E, Confalonieri S, Cavallaro E, Di Fiore PP, Polo S: Molecular mechanisms of coupled monoubiquitination. Nat Cell Biol 2006, 8: I246-1254.

66. Christensen DE, Brzovic PS, Klevit RE: E2-BRCAI RING interactions dictate synthesis of mono- or specific polyubiquitin chain linkages. Nat Struct Mol Biol 2007, 14:94I-948.

67. Mallery DL, Vandenberg CJ, Hiom K: Activation of the E3 ligase function of the BRCAI/BARDI complex by polyubiquitin chains. Embo / 2002, 21:6755-6762.

68. Kim H, Chen J, Yu X: Ubiquitin-binding protein RAP80 mediates BRCAI-dependent DNA damage response. Science 2007 316: I202-I 205.

69. Wang B, Matsuoka S, Ballif BA, Zhang D, Smogorzewska A, Gygi SP, Elledge S): Abraxas and RAP80 form a BRCAI protein complex required for the DNA damage response. Science 2007 316:1194-1198.

70. Hofmann RM, Pickart CM: Noncanonical MMS2-encoded ubiquitin-conjugating enzyme functions in assembly of nove polyubiquitin chains for DNA repair. Cell 1999, 96:645-653.

7I. Ziv Y, Bielopolski D, Galanty Y, Lukas C, Taya Y, Schultz DC, Lukas J, Bekker-Jensen S, Bartek J, Shiloh Y: Chromatin relaxation in response to DNA double-strand breaks is modulated by a novel ATM- and KAP-I dependent pathway. Nat Cell Biol 2006, 8:870-876

72. Huyen Y, Zgheib O, Ditullio RA Jr., Gorgoulis VG, Zacharatos P, Petty TJ, Sheston EA, Mellert HS, Stavridi ES, Halazonetis TD: Methylated lysine 79 of histone $\mathrm{H} 3$ targets 53BP I to DNA double-strand breaks. Nature 2004, 432:406-4II.
73. Botuyan MV, Lee J, Ward IM, Kim JE, Thompson JR, Chen J, Mer G: Structural basis for the methylation state-specific recognition of histone H4-K20 by 53BPI and Crb2 in DNA repair. Cell 2006, I 27: I36I-I373.

74. Kusch T, Florens L, Macdonald WH, Swanson SK, Glaser RL, Yates JR III, Abmayr SM, Washburn MP, Workman JL: Acetylation by Tip60 is required for selective histone variant exchange at DNA lesions. Science 2004, 306:2084-2087.

75. Sloper-Mould KE, Eyre HJ, Wang XW, Sutherland GR, Baker RT: Characterization and chromosomal localization of USP3, a novel human ubiquitin-specific protease. J Biol Chem 1999, 274:26878-26884.

76. Chowdhury D, Keogh MC, Ishii H, Peterson CL, Buratowski S, Lieberman J: gamma-H2AX dephosphorylation by protein phosphatase 2A facilitates DNA double-strand break repair. Mol Cell 2005, 20:80I-809.

77. Tsukuda T, Fleming AB, Nickoloff JA, Osley MA: Chromatin remodelling at a DNA double-strand break site in Saccharomyces cerevisiae. Nature 2005, 438:379-383.

78. Keogh MC, Kim JA, Downey M, Fillingham J, Chowdhury D, Harrison JC, Onishi M, Datta N, Galicia S, Emili A, Lieberman J, Shen X, Buratowski S, Haber JE, Durocher D, Greenblatt JF, Krogan NJ: A phosphatase complex that dephosphorylates gammaH2AX regulates DNA damage checkpoint recovery. Nature 2006, 439:497-50I.

79. Dong Y, Hakimi MA, Chen X, Kumaraswamy E, Cooch NS, Godwin AK, Shiekhattar R: Regulation of BRCC, a holoenzyme complex containing BRCAI and BRCA2, by a signalosome-like subunit and its role in DNA repair. Mol Cell 2003, 12:1087-1099.

80. Chen X, Arciero CA, Wang C, Broccoli D, Godwin AK: BRCC36 is essential for ionizing radiation-induced BRCAI phosphorylation and nuclear foci formation. Cancer Res 2006, 66:5039-5046.

8I. Rayman JB, Takahashi Y, Indjeian VB, Dannenberg JH, Catchpole S, Watson RJ, te Riele H, Dynlacht BD: E2F mediates cell cycledependent transcriptional repression in vivo by recruitment of an HDACI/mSin3B corepressor complex. Genes Dev 2002, 16:933-947.

82. Groth A, Rocha W, Verreault A, Almouzni G: Chromatin challenges during DNA replication and repair. Cell 2007, | 28:72|-733.

83. Vassilev AP, Rasmussen HH, Christensen El, Nielsen S, Celis JE: The levels of ubiquitinated histone $\mathrm{H} 2 \mathrm{~A}$ are highly upregulated in transformed human cells: partial colocalization of uH2A clusters and PCNA/cyclin foci in a fraction of cells in S-phase. I Cell Sci 1995, 108: 1205-1215.

84. Tuttle RL, Bothos J, Summers MK, Luca FC, Halazonetis TD: Defective in mitotic arrest $1 /$ ring finger 8 is a checkpoint protein that antagonizes the human mitotic exit network. Mol Cancer Res 2007, 5:|304-|3|||

85. Plans V, Guerra-Rebollo M, Thomson TM: Regulation of mitotic exit by the RNF8 ubiquitin ligase. Oncogene 2008, 27: I 355- I 365.

86. Voncken JW, Roelen BA, Roefs M, de Vries S, Verhoeven E, Marino S, Deschamps J, van Lohuizen M: Rnf2 (Ring I b) deficiency causes gastrulation arrest and cell cycle inhibition. Proc Natl Acad Sci U S A 2003, 100:2468-2473.

87. Leeb M, Wutz A: Ring I $B$ is crucial for the regulation of developmental control genes and PRCI proteins but not $X$ inactivation in embryonic cells. J Cell Biol 2007, I78:2 19-229.

88. van der Knaap JA, Kumar BR, Moshkin YM, Langenberg K, Krijgsveld J, Heck AJ, Karch F, Verrijzer CP: GMP synthetase stimulates histone H2B deubiquitylation by the epigenetic silencer USP7. Mol Cell 2005, 17:695-707.

89. Cohn MA, Kowal P, Yang K, Haas W, Huang TT, Gygi SP, D'Andrea AD: A UAFI-Containing Multisubunit Protein Complex Regulates the Fanconi Anemia Pathway. Mol Cell 2007, 28:786-797.

90. Huang TT, Nijman SM, Mirchandani KD, Galardy PJ, Cohn MA, Haas W, Gygi SP, Ploegh HL, Bernards R, D'Andrea AD: Regulation of monoubiquitinated PCNA by DUB autocleavage. Nat Cell Biol 2006, 8:339-347.

91. Popov N, Herold S, Llamazares M, Schulein C, Eilers M: Fbw7 and Usp28 regulate myc protein stability in response to DNA damage. Cell Cycle 2007, 6:2327-233 I.

92. Stegmeier F, Rape M, Draviam VM, Nalepa G, Sowa ME, Ang XL, McDonald ER III, Li MZ, Hannon GJ, Sorger PK, Kirschner MW, Harper JW, Elledge SJ: Anaphase initiation is regulated by 
antagonistic ubiquitination and deubiquitination activities. Nature 2007, 446:876-88I.

93. Nijman SM, Huang TT, Dirac AM, Brummelkamp TR, Kerkhoven RM, D'Andrea AD, Bernards R: The Deubiquitinating Enzyme USP I Regulates the Fanconi Anemia Pathway. Mol Cell 2005, 17:33I-339.

94. Poeck B, Fischer S, Gunning D, Zipursky SL, Salecker I: Glial cells mediate target layer selection of retinal axons in the developing visual system of Drosophila. Neuron 200I, 29:99-II3.

Publish with Biomed Central and every scientist can read your work free of charge

"BioMed Central will be the most significant development for disseminating the results of biomedical research in our lifetime. " Sir Paul Nurse, Cancer Research UK

Your research papers will be:

- available free of charge to the entire biomedical community

- peer reviewed and published immediately upon acceptance

- cited in PubMed and archived on PubMed Central

- yours - you keep the copyright

Submit your manuscript here:

http://www.biomedcentral.com/info/publishing_adv.asp 